\title{
DEATH AND THROMBOEMBOLIC DISEASE AFTER TOTAL HIP REPLACEMENT
}

\author{
A SERIES OF 1162 CASES WITH NO ROUTINE CHEMICAL PROPHYLAXIS
}

DAVID WARWICK. M. H. WILLIAMS, G. C. BANNISTER

From the University of Bristol, England

We studied 1162 consecutive total hip replacements (THR) to establish the incidence of fatal pulmonary embolism (PE), clinical non-fatal PE and deep-vein thrombosis (DVT) in the six months after surgery. Chemical thromboprophylaxis had not been routinely used. We used a validated questionnaire supplemented by post-mortem records and a review of the clinical notes. Follow-up was $100 \%$.

The death rate from PE was $0.34 \%$ (95\% CI 0.09 to 0.88), with one fatal $P E$ after discharge 40 days after operation. The clinical $P E$ rate confirmed by imaging was $1.20 \%$ (CI 0.65 to 2.02 ), with $0.7 \%$ of patients readmitted. The venographically-confirmed clinical DVT rate was $1.89 \%$ (CI 1.11 to 2.76 ), with $1.13 \%$ readmitted. The total thromboembolic morbidity was $3.4 \%$ (95\% CI $2.5 \%$ to $4.7 \%$ ); prophylaxis to reduce this would be justifiable if the complications of such prophylaxis did not produce an alternative morbidity.

The fatal PE rate after THR without routine chemical prophylaxis was low; a very large randomised clinical trial would be required to demonstrate directly whether any prophylactic measure could reduce this. There is a large discrepancy between the high DVT rate reported in clinical trials using universal screening venography and the symptomatic DVT rate shown in this study. We found insufficient evidence to recommend continuing thromboprophylaxis after discharge from hospital.

J Bone Joint Surg [Br] 1995;77-B:6-10.

Received 31 March 1994: Accepted 24 June 1994

D. Warwick, FRCS. Lecturer in Orthopaedic Surgery, University of Bristol

G. C. Bannister, MD, MCh Orth, FRCS, FRCS Ed, FRCS Ed(Orth), Consultant Orthopaedic Surgeon

Winford Unit, Avon Orthopaedic Centre, Southmead Hospital, Bristol BS10 5NB. UK.

M. H. Williams. MA, MRCP. MFPHM. Consultant Senior Lecturer in Epidemiology and Public Health Medicine

University of Bristol, Canynge Hall, Bristol BS8 2PR. UK.

Correspondence should be sent to Mr D. Warwick.

O1995 British Editorial Society of Bone and Joint Surgery

$0301-620 \mathrm{X} / 95 / 1922 \$ 2.00$
Thromboembolism is one of the most common and potentially serious complications of total hip replacement (THR). Early series suggested that the mortality from pulmonary embolism (PE) could be as high as $2.3 \%$ to $3.4 \%$ (Coventry, Nolan and Beckenbaugh 1973; Johnson, Green and Charnley 1977) and such historical control figures are still repeated in support of thromboprophylaxis (European Consensus Statement 1991) or a particular prophylactic regimen (Paiement et al 1993). More recent series suggest an overall mortality of $0.95 \%$ to $1.1 \%$, with that due to PE only a proportion of this (Sheppeard et al 1981; Seagroatt et al 1991). It seems that the death rate from PE may be falling and that updated mortality figures are required.

Venographic studies have shown an incidence of deepvein thrombosis (DVT) without prophylaxis of about $45 \%$, but only a small proportion of these thrombi present clinically as DVT or PE. Similarly, screening ventilation-perfusion (V/Q) studies have shown an incidence of asymptomatic non-fatal PE of about $20 \%$, but the proportion of emboli which are symptomatic is considerably less.

Some patients who have had THR are readmitted after discharge with symptomatic DVT or PE (Bergqvist 1993); this raises the question of prolonged prophylaxis. The only available figure for the proportion readmitted was provided by the Oxford Record Linkage study; $0.73 \%$ needed readmission with venous thrombosis or embolism within 28 days of discharge (Seagroatt et al 1991).

We have studied a large cohort of patients who did not have routine chemical prophylaxis to determine the incidence of clinical thromboembolism before and after discharge, and the mortality from PE.

\section{PATIENTS AND METHODS}

We reviewed all the records of 1112 patients who had had 1162 primary or revision THR performed in the years 1990 and 1991. The patients were treated at one specialised centre by 12 consultant-led surgical teams, serving a population of about one million. There were 18 bilateral procedures, and 112 revision operations. Fifty patients had two replacements within the two-year period.

The standard practice was to use antiembolism stockings and early mobilisation. The choice of general, epidural or spinal anaesthesia was made by the anaesthetist, and pos- 
Table I. Questionnaire sent to all patients

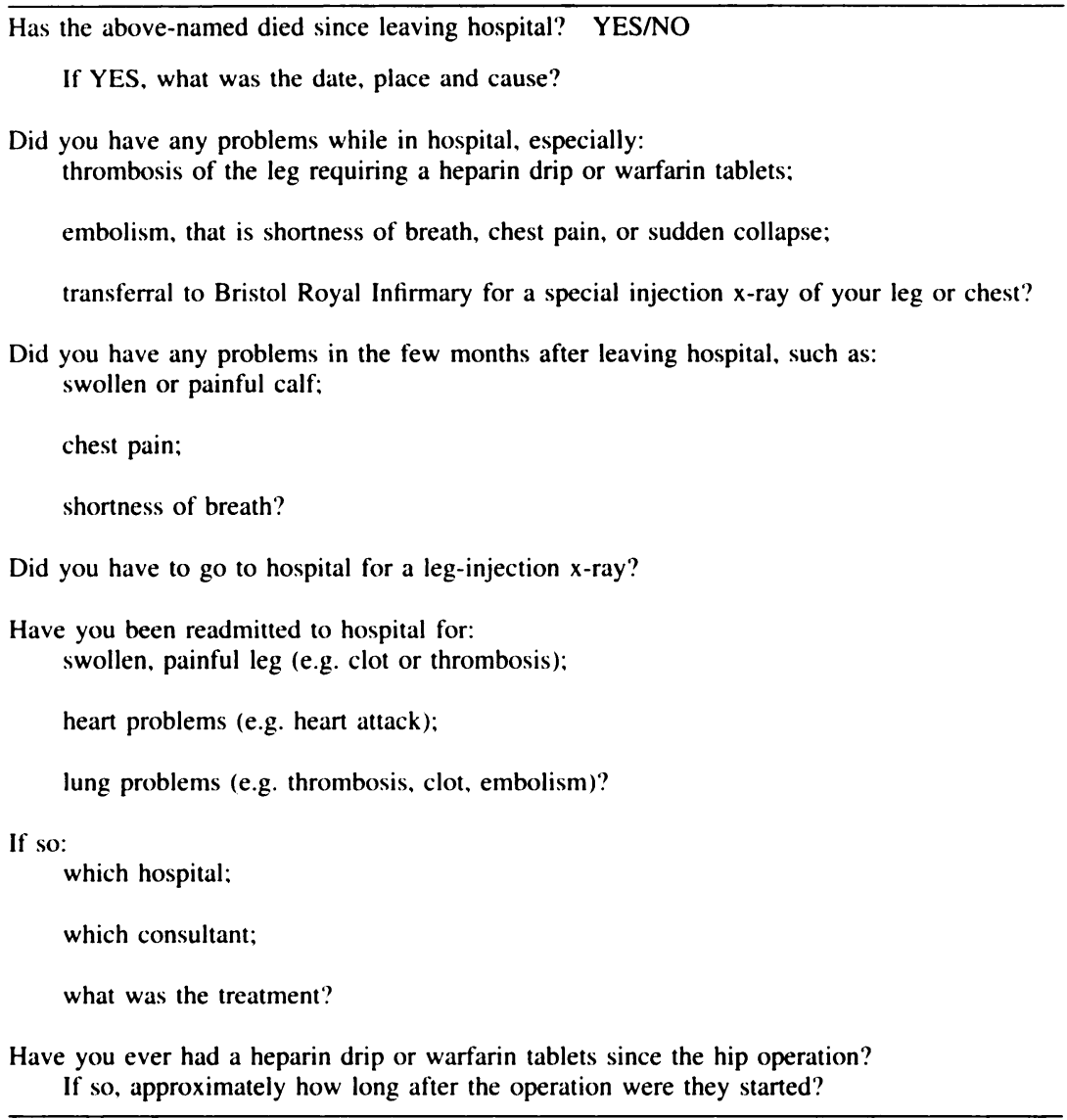

terior, lateral and anterolateral approaches were used. Anticoagulant prophylaxis was not used routinely, but was reserved for those considered to be at the greatest risk of thromboembolism.

A questionnaire (Table I) was sent to 1087 patients at least six months after the operation, and followed by a second questionnaire if no response was received within two months (excluding 25 who were known to have died). Failure to respond to the second questionnaire led to a third questionnaire; if this was not returned an alternative address was sought through the general practitioner or Family Health Services Authority. The full hospital records of residual non-responders were then retrieved and studied.

If a patient had died or the questionnaire showed any suggestion of a thromboembolic event or the use of oral anticoagulants, the hospital records were retrieved. Death within six months was assumed to be potentially related to the operation and its cause was established by reference to the post-mortem record or death certificate.

To validate the accuracy of the questionnaire a random sample of 109 medical records (10\%) of those with questionnaire responses which were negative for thromboembolic events was scrutinised for any evidence of such events.

We have given $95 \%$ confidence intervals where they are appropriate, using the formula for the standard error of a proportion based on the normal approximation of the Poisson distribution.

\section{RESULTS}

All 1112 patients were traced.

Validation of questionnaire. No deaths or thromboembolic episodes were identified in the clinical records of the random sample of 109 patients who had returned a negative questionnaire. All of this sample cohort had used antiembolism stockings. Spinal or epidural anaesthesia had been given to $59.6 \%$ and prophylactic anticoagulants to $10.6 \%$.

The positive predictive value (true positive divided by total positive) of the questionnaire for proven thromboembolism was $50.6 \%$ (40/79).

There were 40 non-responders ( 42 THRs) of whom two had died at least one year after surgery and two had been readmitted, one for a venogram which was normal, and one for a V/Q scan which was positive. The total morbidity from thromboembolic complications was $3.4 \%(95 \% \mathrm{CI}$ $2.5 \%$ to $4.7 \%$ ).

Deaths (Table II). Seventeen patients ( $1.46 \%$ of procedures) had died within six months of surgery, none of them after bilateral THR. One patient died at seven months; he 
D. WARWICK, M. H. WILLIAMS, G. C. BANNISTER

Table II. Deaths within six months of total hip replacement

\begin{tabular}{|c|c|c|c|}
\hline $\begin{array}{l}\text { Day of } \\
\text { death }\end{array}$ & $\begin{array}{l}\text { Age of } \\
\text { patient } \\
\text { (yr) }\end{array}$ & Post-mortem & Death certificate \\
\hline 1 & 78 & Pulmonary embolism & \\
\hline 2 & 68 & Pulmonary embolism & \\
\hline $2 \mathrm{R}^{*}$ & 80 & Myocardial infarct, congestive cardiac failure & \\
\hline 2 & 75 & Myocardial infarct & \\
\hline 5 & 73 & Pulmonary embolism & \\
\hline 5 & 80 & Myocardial infarct & \\
\hline $15+$ & 87 & Myocardial infarct & \\
\hline 20 & 80 & $\begin{array}{l}\text { Left ventricular failure } \\
\text { Pneumonia }\end{array}$ & \\
\hline 21 & 67 & & $\begin{array}{l}\text { Bronchopneumonia } \\
\text { Septic THR }\end{array}$ \\
\hline $25 \mathrm{R}^{*}$ & 80 & & Cerebrovascular accident \\
\hline 38 & 71 & . & $\begin{array}{l}\text { Peritonitis } \\
\text { Perforated duodenal } \\
\text { ulcer }\end{array}$ \\
\hline $40 \dagger$ & 70 & Pulmonary embolism, DVT & \\
\hline $42 \dagger$ & 74 & Myocardial infarct & \\
\hline $52 \dagger$ & & $\begin{array}{l}\text { Haemorrhage from } \\
\text { oesophageal ulcer }\end{array}$ & \\
\hline 60 & 74 & & $\begin{array}{l}\text { Bronchopneumonia } \\
\text { Cerebrovascular accident }\end{array}$ \\
\hline $160 \dagger$ & 75 & & Carcinoma of pancreas \\
\hline $180+$ & & Carcinoma of pancreas & \\
\hline
\end{tabular}

had been readmitted 12 days postoperatively with an isolated proximal thrombosis and was anticoagulated for three months. At six months he was admitted with a myocardial infarct and subsequent PE. He was again anticoagulated and died one month later from the complications of gastrointestinal haemorrhage.

Fatal pulmonary embolism (Table II). Four patients died from pulmonary embolism, three as inpatients and one after discharge. The patient who died after discharge had had DVT after a cholecystectomy 16 years previously, and had been given a six-week course of warfarin started on the second day after THR. The course had been stopped four days before his death. The rate of fatal PE was therefore
$4 / 1162(0.34 \%$, CI 0.09 to 0.88$)$ and the rate of fatal PE after discharge was $1 / 1151(0.087 \%, \mathrm{CI} 0$ to 0.48$)$.

Pulmonary embolism (Table III). Nine patients had an inpatient V/Q scan, which was positive for $P E$ in six. Nine patients were readmitted for a V/Q scan, which was positive for PE in eight. The overall incidence of symptomatic, proven PE was $14 / 1162$ (1.20\%, CI 0.657 to 2.02$)$, and the readmission rate for proven $\mathrm{PE}$ was $8 / 1151(0.7 \%$, CI 0.30 to 1.36). The average delay between the onset of symptoms and the V/Q scan was 2.4 days (0 to 9 ). Two patients were readmitted with painful legs; they had venography with negative results, but further symptoms led to positive V/Q scans for PE on the following day.

Table III. Details of patients having pulmonary embolism

\begin{tabular}{|c|c|c|c|c|c|c|c|}
\hline \multirow[b]{2}{*}{ Case } & \multirow[b]{2}{*}{$\begin{array}{l}\text { Age } \\
\text { (yr) }\end{array}$} & \multicolumn{3}{|l|}{ Day } & \multirow[b]{2}{*}{ Readmission } & \multirow{2}{*}{$\begin{array}{l}\text { Spinal or } \\
\text { epidural } \\
\text { anaesthetic }\end{array}$} & \multirow{2}{*}{$\begin{array}{l}\text { Anti- } \\
\text { coagulant } \\
\text { prophylaxis }\end{array}$} \\
\hline & & $\begin{array}{l}\text { Onset of } \\
\text { symptoms }\end{array}$ & $\begin{array}{l}\mathrm{V} / \mathrm{Q} \\
\text { scan }\end{array}$ & Discharge & & & \\
\hline 1 & 56 & 3 & 7 & & & & \\
\hline 2 & 59 & 4 & 5 & & & & \\
\hline 3 & 74 & 4 & 7 & & & & \\
\hline 4 & 74 & 7 & 8 & & & & \\
\hline 5 & 73 & 7 & 8 & & & + & \\
\hline 6 & 72 & 9 & 18 & 12 & & + & \\
\hline 7 & 63 & 11 & 11 & 10 & + & & \\
\hline 8 & 76 & 14 & 20 & 14 & + & & \\
\hline 9 & 63 & 17 & 17 & 9 & + & + & \\
\hline 10 & 67 & 17 & 17 & 13 & + & + & \\
\hline 11 & 71 & 17 & 19 & 18 & + & + & + \\
\hline 12 & 68 & 20 & 20 & 13 & + & + & \\
\hline 13 & 78 & 27 & 33 & 14 & + & & \\
\hline 14 & 57 & 36 & 36 & 7 & + & + & \\
\hline
\end{tabular}


Table IV. Details of patients having deep-vein thrombosis

\begin{tabular}{|c|c|c|c|c|c|c|c|c|}
\hline \multirow[b]{2}{*}{ Case } & \multirow[b]{2}{*}{$\begin{array}{l}\text { Age } \\
(\mathbf{y r})\end{array}$} & \multicolumn{3}{|l|}{ Day } & \multirow[b]{2}{*}{ Readmission } & \multirow[b]{2}{*}{ Type of thrombosis } & \multirow{2}{*}{$\begin{array}{l}\text { Spinal or } \\
\text { epidural } \\
\text { anaesthetic }\end{array}$} & \multirow{2}{*}{$\begin{array}{l}\text { Anti- } \\
\text { coagulant } \\
\text { prophylaxis }\end{array}$} \\
\hline & & $\begin{array}{l}\text { Onset of } \\
\text { symptoms }\end{array}$ & Venogram & Discharge & & & & \\
\hline 1 & 73 & 3 & 5 & & & $\begin{array}{l}\text { Calf and isolated } \\
\text { femoral }\end{array}$ & + & \\
\hline 2 & 76 & 6 & 8 & & & Calf & & \\
\hline 3 & 78 & 7 & 10 & & & Full leg & + & \\
\hline 4 & 73 & 7 & 12 & & & $\begin{array}{l}\text { Calf and isolated } \\
\text { femoral }\end{array}$ & & \\
\hline 5 & 76 & 7 & 8 & & & Minor calf & & \\
\hline 6 & 53 & 9 & 18 & 8 & + & Calf and popliteal & + & \\
\hline 7 & 68 & 10 & 10 & & & Calf and popliteal & + & \\
\hline 8 & 68 & 10 & 11 & & & Isolated femoral & & \\
\hline 9 & 66 & 10 & 11 & & & Full leg & & \\
\hline 10 & 77 & 10 & 14 & 11 & + & Isolated femoral & & \\
\hline 11 & 74 & 12 & 14 & 10 & + & Isolated femoral & & \\
\hline 12 & 46 & 14 & 15 & 10 & + & Full leg & & \\
\hline 13 & 59 & 14 & 19 & 7 & + & Full leg & + & \\
\hline 14 & 61 & 15 & 15 & 8 & + & Full leg & & \\
\hline 15 & 65 & 15 & 21 & 13 & + & Calf & & \\
\hline 16 & 81 & 20 & 23 & & & Full leg & & + \\
\hline 17 & 75 & 20 & 40 & 11 & + & Full leg & & \\
\hline 18 & 49 & 28 & 28 & 10 & + & Minor calf & + & \\
\hline 19 & 73 & 35 & 50 & 9 & + & Full leg & & \\
\hline 20 & 71 & 40 & 40 & 11 & + & Full leg & & \\
\hline 21 & 58 & 140 & 150 & 11 & + & Full leg & & + \\
\hline 22 & 73 & 150 & 150 & 13 & + & Full leg & + & + \\
\hline
\end{tabular}

Deep-vein thrombosis (Table IV). Fourteen patients had inpatient venograms: nine were positive for DVT, at an average delay between the onset of symptoms and the venogram of four days (0 to 20). A total of 23 symptomatic patients were readmitted for venography: 13 were positive and 10 were negative. The overall venographically-proven DVT rate was therefore $22 / 1162$ (1.89\%, CI 1.11 to 2.76 ), and the readmission rate for proven DVT was $13 / 1151$ (1.13\%, CI 0.60 to 1.93$)$.

Five patients had anticoagulants prescribed empirically for DVT without venographic proof. One patient who presented with a DVT after 140 days had dislocated her prosthesis at two weeks, had then been placed in a brace for eight weeks and given low-dose heparin for one week. One patient who presented with DVT after 150 days had been taking adjusted-dose warfarin for three months after THR, because of a history of previous DVT.

\section{DISCUSSION}

We consider that the comprehensive follow-up, the high post-mortem rate for the early deaths and the high negative predictive value of the questionnaire have confirmed the validity of our results.

Our inpatient, all-cause mortality rate of $0.86 \%$ (10/1162) compares with the $0.63 \%$ reported by Sheppeard et al (1981) and the 90-day mortality rate of $1.3 \%$ (15/1162) compares with the $1.1 \%$ reported by Seagroatt et al (1991). It is clear from all three studies that the oftquoted PE mortality figures of $2.3 \%$ to $3.4 \%$ after THR are misleading. It should be noted that our patients and those reported from Oxford by Seagroatt et al (1991) were not routinely given chemical antithrombotic prophylaxis. The rate of $0.34 \%$ of fatal PE which we found represents 100 deaths for the 30000 THRs performed annually in England; and the upper confidence limit of $0.88 \%$ suggests 265 deaths per annum.

Prophylaxis against thromboembolism remains controversial. Despite considerable pressure from lawyers and from other branches of the medical profession (ParkerWilliams and Vickers 1991; Campling et al 1993), many orthopaedic surgeons are reluctant to use chemical prophylaxis because of doubts about efficacy and possible haemorrhagic complications (Owen and Coorsh 1992). Charnley abandoned the use of adjusted-dose phenindione because the benefit from reduction of PE mortality was matched by an increased mortality from gastrointestinal haemorrhage (Crawford, Hillman and Charnley 1968). Coventry et al (1973) recommended delay in warfarin anticoagulation to the fifth postoperative day but this would have failed to cover three of the four fatal PE which we report. Metaanalysis shows that both low-dose, unfractionated heparin and low-molecular-weight heparin substantially reduce the incidence of venographic DVT after THR from about $45 \%$ to about 23\% (Collins et al 1988) and about 19\% (Jørgenson, Wille-Jørgenson and Hauch 1993), although with some haemorrhagic side-effects. This reduction in DVT has been extrapolated to imply a reduction in incidence of fatal PE, but no study has been powerful enough to demonstrate directly such a reduction after THR. It would require a randomised study of $\mathbf{2 8 0 0 0}$ patients to show halving of the fatal $\mathrm{PE}$ rate from $0.34 \%$ to $0.17 \%$ at the $95 \%$ significance level with $80 \%$ power.

Seagroatt et al (1991) report a readmission rate for 
symptomatic thromboembolic complications of $0.73 \%$ within 28 days of discharge after THR; our rate for the same period was $1.39 \%$ (CI 0.65 to $1.95,16 / 1151$ surviving patients). It is uncertain whether the thrombi leading to readmission were present but symptomless at the time of discharge or whether they developed later. There is no evidence to suggest that prolonged prophylaxis may influence such late complications, and no cost-benefit or riskbenefit studies have been published to support such a policy.

Various factors complicate the design of any study which aims to assess the efficacy of thromboprophylaxis after hospital discharge. It is known that venous thrombosis can occur despite normal venography on discharge if anticoagulation is stopped on leaving hospital (Matzsch et al 1990; Tremaine, Choroszy and Menking 1991), and the possibility of rebound thrombosis after stopping prophylaxis has been identified by sequential ${ }^{131}$ I studies (Sikorski, Hampson and Staddon 1981). There are no data on which to base rational timing for repeated screening for asymptomatic thromboembolism after discharge, and patients may not comply with a protocol requiring repeated injections of anticoagulant once inpatient supervision has ended.

The problem of postoperative leg swelling and its relationship to DVT after THR has not been studied.

Conclusions. The fatal PE rate after THR with selective chemical prophylaxis was low but nevertheless represented from 100 up to 265 deaths in England each year. A very large randomised clinical trial would be required to demonstrate directly whether any prophylactic measure could reduce this rate further; reliance on the indirect marker of DVT is therefore more feasible. There was a discrepancy between the high DVT rate shown by universal screening venography and the clinical DVT rate demonstrated in this study. The total early morbidity from thromboembolic disease was considerable $(3.4 \%)$; prophylaxis to reduce this would be justifiable if the complications of such prophylaxis did not produce an alternative morbidity. There is insufficient evidence to recommend thromboprophylaxis after discharge from hospital.
This work was supported by the Laming Evans Orthopaedic Fellowship and the South West Regional Health Authority Research Committee. The assistance of $\mathrm{Mr}$ Gordon Wadey of Southmead Hospital Quality Assurance Department, is appreciated.

No benefits in any form have been received or will be received from a commercial party related directly or indirectly to the subject of this article.

\section{REFERENCES}

Bergqvist D. Long-term prophylaxis following orthopaedic surgery. Haemostasis 1993;23:Suppl:27-31.

Campling EA, Devlin HB, Hoile RW, Lunn JN. The report of the National Confidential Enquin into Perioperative Deaths 1991/1992. London: The National Confidential Enquiry into Perioperative Deaths. 1993.

Collins R, Scrimgeour A, Yusuf S, Peto R. Reduction in fatal pulmonary embolism and venous thrombosis by perioperative administration of subcutaneous heparin: an overview of results of randomized trials in general, orthopaedic and urological surgery. $N$ Engl $J$ Med 1988;18:1162-73.

Coventry MB, Nolan DR, Beckenbaugh RD. “Delayed" prophylactic anticoagulation: a study of results and complications in 2012 total hip arthroplasties. J Bone Joint Surg [Am] 1973:55-A:1487-92.

Crawford WJ, Hillman F, Charnley J. A clinical trial of prophylactic anticoagulant therapy in elective hip surgery. Centre for hip surgery. Wrightington Hospital, 1968: Internal Publication 14.

European Consensus Statement. Prevention of venous embolism. London: Med-Orion, 1992.

Johnson R, Green JR, Charnley J. Pulmonary embolism and its prophylaxis following the Charnley total hip replacement. Clin Orthop 1977:127:123-32.

Jørgenson LN, Wille-Jørgenson P, Hauch O. Prophylaxis of postoperative thromboembolism with low-molecular weight heparins. $\mathrm{Br} J$ Surg 1993:80:689-704.

Matzsch T, Bergqvist D, Fredin H, Hedner U. Low molecular weight heparin compared with dextran as prophylaxis against thrombosis after total hip replacement. Acta Chir Scand 1990:156:445-50.

Owen TD, Coorsh J. The use of thromboprophylaxis in total hip replacement surgery: are the attitudes of orthopaedic surgeons changing? $J R$ Soc Med 1992:85:679-81.

Paiement GD, Wessinger SJ, Hughes R, Harris WH. Routine use of adjusted low-dose warfarin to prevent venous thromboembolism after total hip replacement. J Bone Joint Surg [Am] 1993:75-A:893-8.

Parker-Williams J, Vickers R. Major orthopaedic surgery on the leg and thromboembolism. BMJ 1991:303:531-2

Seagroatt V, Tan HS, Goldacre M, et al. Elective total hip replacement: incidence, emergency readmission rate and postoperative mortality. $\mathrm{Br}$ Med J 1991:303:1431-5.

Sheppeard H, Henson J, Ward DJ, O'Connor BT. A clinico-pathological study of fatal pulmonary embolism in a specialist orthopaedic hospital. Arch Orthop Traumat Surg 1981:99:65-71.

Sikorski JM, Hampson WG, Staddon GE. The natural history and aetiology of deep vein thrombosis after total hip replacement. $J$ Bone Joint Surg [Br] 1981:63-B:171-7.

Tremaine MD, Choroszy CJ, Menking SA. Deep vein thrombosis in the total hip arthroplasty patient after hospital discharge. $J$ Vasc Technology 1991:15:205-6. 